\title{
Calcium Metabolism in Newborn Infants
}

\author{
THE INTERRELATIONSHIP OF PARATHYROID FUNCTION \\ AND CALCIUM, MAGNESIUM, AND PHOSPHORUS \\ METABOLISM IN NORMAL, "SICK," AND \\ HYPOCALCEMIC NEWBORNS
}

\author{
Louis Davm and Constantine S. Anast
}

From the Department of Pediatrics, University of Missouri and Veterans

Administration Hospital, Columbia, Missouri 65201

A B S T R A C T Serum immunoreactive parathyroid hormone (iPTH) and plasma total calcium, ionized calcium, magnesium, and phosphorus levels were determined during the first 9 days of life in 137 normal term infants, 55 "sick" infants, and 43 hypocalcemic ( $\mathrm{Ca}$ $<7.5 \mathrm{mg} / 100 \mathrm{ml} ; \mathrm{Ca}^{++}<4.0 \mathrm{mg} / 100 \mathrm{ml}$ ) infants.

In the cord blood, elevated levels of plasma $\mathrm{Ca}^{++}$and $\mathrm{Ca}$ were observed, while levels of serum iPTH were either undetectable or low. In normal newborns during the first $48 \mathrm{~h}$ of life there was a decrease in plasma $\mathrm{Ca}$ and $\mathrm{Ca}^{++}$, while the serum iPTH level in most samples remained undetectable or low; after $48 \mathrm{~h}$ there were parallel increases in plasma $\mathrm{Ca}$ and $\mathrm{Ca}^{++}$and serum iPTH levels. Plasma $\mathrm{Mg}$ and $\mathrm{P}$ levels increased progressively after birth in normal infants.

In the sick infants, plasma $\mathrm{Ca}, \mathrm{Ca}^{++}$and $\mathrm{P}$ levels were significantly lower than in the normal newborns, while no significant differences were found in the plasma $\mathrm{Mg}$ levels. The general pattern of serum iPTH levels in the sick infants was similar to that observed in the normal group, though there was a tendency for the increase in serum iPTH to occur earlier and for the iPTH levels to be higher in the sick infants.

In the hypocalcemic infants, plasma $\mathrm{Mg}$ levels were consistently lower than in the normal infants after $24 \mathrm{~h}$ of age, while no significant differences were found in

Dr. David was supported by a grant from the Direction Générale des Relations Culturelle, Scientifique et Technique, Paris, France and by Senior Fulbright-Hays program; also by Wyeth Laboratories Grant 59282601 and by Manschott Hudson Research Grant 58482601. Dr. Anast is the recipient of Career Research Development Award HD-39654 from the National Institutes of Child Health and Human Development.

Received for publication 7 November 1973 and in revised form 28 March 1974. the plasma $\mathrm{P}$ levels. Hyperphosphatemia was uncommon and did not appear to be a contributing factor in the pathogenesis of hypocalcemia in most infants. Most of the hypocalcemic infants, including those older than $48 \mathrm{~h}$, had inappropriately low serum iPTH levels.

Evidence obtained from these studies indicates that parathyroid secretion is normally low in the early newborn period and impaired parathyroid function, characterized by undetectable or low serum iPTH, is present in most infants with neonatal hypocalcemia. Additional unknown factors appear to contribute to the lowering of plasma $\mathrm{Ca}$ in the neonatal period. The net effect of unknown plasma hypocalcemic factor (s) on the one hand and parathyroid activity on the other may account for differences in plasma $\mathrm{Ca}$ levels observed between normal, sick, and hypocalcemic infants. Depressed plasma $\mathrm{Mg}$ is frequently present in hypocalcemic infants. To what degree the hypomagnesemia reflects parathyroid insufficiency or the converse, to what degree parathyroid insufficiency and hypocalcemia are secondary to hypomagnesemia, is uncertain.

\section{INTRODUCTION}

Though poorly understood, the regulation of calcium homeostasis in the newborn period has been of considerable interest. At birth, the plasma calcium ( $\mathrm{Ca}$ ) level in cord blood exceeds that in maternal blood. During the early days of life, the plasma Ca level progressively decreases in normal infants, so that by the second or third day of life, the level is lower than that found in older infants and children. In most normal full-term infants the plasma $\mathrm{Ca}$ level returns to normal by 10 days of life. The decline in plasma $\mathrm{Ca}$ in the newborn period is greater in infants who are not fed or who receive cow's 
milk than in breast-fed infants, and greatest in infants who are sick and/or the products of abnormal pregnancies and labors, including premature infants, infants of diabetic mothers, and infants with asphyxia (1). In some infants the plasma $\mathrm{Ca}$ level falls to pathologically low levels and tetany or convulsions may result.

The possible role of transient hypoparathyroidism as an etiologic factor in neonatal hypocalcemia has received considerable attention, but there has been little direct evidence to support this hypothesis. The development in our laboratory of a sensitive radioimmunoassay for the determination of parathyroid hormone in small quantities of serum has given us the opportunity to assess parathyroid function in the newborn more directly. In a preliminary report, we presented data restricted to measurements of plasma $\mathrm{Ca}$ and immunoreactive parathyroid hormone (iPTH) ${ }^{1}$ in a limited number of normal and hypocalcemic newborn infants during the first $90 \mathrm{~h}$ of life (2). The results suggested that parathyroid function was depressed during the first hours of life in normal newborn infants; in addition, low levels of serum iPTH were found in several of the hypocalcemic infants studied. Because the data in the preliminary study were insufficient to be conclusive and because the age range included only the first $90 \mathrm{~h}$ of life, this aspect of our investigation, which comprises one segment of this report, has been extended in the following ways: $(a)$ the total aggregate of normal and hypocalcemic infants has been increased by approximately threefold, $(b)$ the age range studied has been extended from the first $90 \mathrm{~h}$ of life to the first $158 \mathrm{~h}$ of life in the normal newborns and to the first $216 \mathrm{~h}$ of life in the hypocalcemic infants, and $(c)$ in addition, arterial and venous umbilical cord blood values are reported. The results of this phase of the study firmly establish the pattern of parathyroid function in normal neonates which, in turn, provides an important and indispensable data base for the more comprehensive studies of hypocalcemic infants and, equally important, for the additional new studies briefly discussed in the following paragraphs and detailed in the body of this report.

It has been well established that various complications of pregnancy, delivery, and the neonatal period predispose the newborn infant to develop hypocalcemia (1). The reason for this is unknown and it is not clear why some infants who are subjected to these complications develop hypocalcemia while others do not. In an effort to gain insight into this problem, we studied 55 infants without evidence of hypocalcemia who were hospitalized in the intensive care unit of the newborn nursery because of a variety of complications of pregnancy, delivery, and the newborn period. The findings in this group, desig-

\footnotetext{
${ }_{1}$ Abbreviations used in this paper: $\mathrm{iPTH}$, immunoreactive parathyroid hormone; $\mathrm{P}$, inorganic phosphorus.
}

nated as "sick" infants, are compared to the findings in the hypocalcemic infants, most of whom were subjected to complications similar to those observed in the sick infants.

The role of hyperphosphatemia and its influence on neonatal calcium metabolism and parathyroid function has been a subject of concern and debate for many years (1). Because early reports relied on indirect studies of parathyroid function, our knowledge of the interrelationship of phosphorus metabolism and parathyroid activity in the neonatal period is uncertain. The results of the studies to be presented allow for a more direct assessment of this interrelationship than has heretofore been possible.

In recent years an association between hypocalcemia and hypomagnesemia has been observed in newborn infants as well as in older children and adults. Recent evidence obtained in our laboratory demonstrated that parathyroid hormone synthesis and/or secretion was impaired in a hypomagnesemic adult, and similar findings were reported in an 8-yr-old child by Suh, Tashjian, Matsuo, Parkinson and Fraser $(3,4)$. However, there is little information on the influence of magnesium on calcium homeostasis in the newborn. In this report we explore the role of magnesium in neonatal hypocalcemia, and the possible influence of this cation on neonatal parathyroid function.

Though it has been the subject of a number of studies, it is apparent that the underlying pathophysiologic mechanism responsible for neonatal hypocalcemia has not been clearly defined. As indicated above, several factors have been implicated in this disorder, including transient hypoparathyroidism, hyperphosphatemia, hypomagnesemia, and various complications of pregnancy and the neonatal period. In the present study each of these factors is critically examined in an effort to further our understanding of neonatal calcium metabolism. The results provide data that permit a comparison of the interrelationship of parathyroid function and calcium, magnesium, and phosphorus metabolism in normal, sick, and hypocalcemic newborn infants.

\section{METHODS}

Three groups of newborn infants were studied during the first 9 days of life:

Normal full-term infants. This group consisted of 137 term infants born after normal pregnancy and housed in the nursery of the University of Missouri Medical Center. Delivery and neonatal period were uneventful in all cases. Distilled water was fed at $3 \mathrm{~h}$ of age, while Enfamil formula (Mead Johnson Laboratories, Evansville, Ind.) was offered every $4 \mathrm{~h}$ starting at 5-7 h of age. Each $100 \mathrm{ml}$ of Enfamil contains $58 \mathrm{mg}$ of calcium, $45 \mathrm{mg}$ of phosphorus, $5 \mathrm{mg}$ of magnesium, and $42 \mathrm{IU}$ of vitamin D.

Sick infants. This group consisted of 55 infants without evidence of hypocalcemia (plasma $\mathrm{Ca}>7.5 \mathrm{mg} / 100 \mathrm{ml}$ ) who were hospitalized in the intensive care unit of the 
newborn nursery because of a variety of complications of pregnancy, delivery, and the neonatal period. The complications included cesarean section $(n=4)$, maternal diabetes $(n=9)$, sepsis $(n=9)$, asphyxia $(n=8)$, hyperbilirubinemia $(n=8)$, placental abnormalities $(n=1)$, and respiratory distress syndrome $(n=6), 34$ infants had a gestational age equal to or greater than 38 wk while 21 were premature (gestational age 33-37 wk). Gestational age was estimated by the scoring system of Dubowitz, Dubowitz, and Goldberg (5). In 21 infants there were signs of increased neuromuscular irritability. There was no uniformity in the type of alimentation in this group because several infants were referred from nurseries outside of the Medical Center. 27 of the infants had received or were receiving intravenous fluids at the time of the study.

Hypocalcemic newborn infants. This group consisted of 43 infants who had plasma $\mathrm{Ca}$ levels less than $7.5 \mathrm{mg} / 100$ ml. 23 infants had a gestational age equal to or greater than 38 wk, while 20 were considered to be premature (3237 wk of gestational age). In 34 of the 43 infants there were definite signs of increased neuromuscular irritability including twitching, tetany, and convulsions, while in 9 infants signs of increased neuromuscular activity were questionable. In 37 cases the pregnancy, delivery, and/or neonatal course was abnormal. The most frequent complications were cesarean section $(n=19)$, maternal diabetes ( $n$ $=9)$, respiratory distress syndrome $(n=6)$, asphyxia ( $n$ $=8)$, sepsis $(n=4)$, hyperbilirubinemia associated with $\mathrm{Rh}$ or ABO incompatibility $(n=8)$, and placental abnormalities $(n=3)$. As in the sick group, the type of alimentation was variable in this group, and 24 infants were receiving or had received intravenous fluids at the time of the study. The incidence of various complications observed in the sick and hypocalcemic infants is compared in Table I.

Blood sampling. Arterial and venous cord blood samples were drawn separately by puncture of the main placental arteries and veins immediately after delivery of the placenta. In all normal infants, blood specimens were collected by arm or scalp vein puncture with a scalp vein needle; collections were made in the late morning between 2 and $4 \mathrm{~h}$ after a feeding. In both the hypocalcemic and sick infants, blood samples were obtained either by peripheral vein puncture or from umbilical artery catheters, employed for infusion of fluids. In all of the hypocalcemic infants, blood samples were obtained before calcium therapy.

Laboratory procedures. Serum levels of iPTH were determined by a double-antibody radioimmunoassay technique developed in our laboratory (6). The antiserum used in this study (GP.03) was obtained by immunizing a guinea pig with partially purified bovine parathyroid hormone and is used at a final dilution of $1: 100,000$. In gel filtration studies of serum from patients with primary and secondary hyperparathyroidism, GP.03 antiserum detected a peak of immunoreactivity that corresponded to the [ $\left.{ }^{100} \mathrm{I}\right]$ bovine parathyroid hormone marker ( $\mathrm{mol}$ wt 9,500) and a larger peak with a trailing shoulder that eluted later than the marker (6). This indicates that our antiserum GP.03 recognizes circulating forms of parathyroid hormone, which includes the 84-amino acid peptide ( $\mathrm{mol}$ wt 9,500 ) as well as smaller immunoreactive species (7-9). Human hyperparathyroid serum is used as the reference standard in the assay and the concentration of iPTH in unknown serum samples is expressed as microliter equivalents of the standard hyperparathyroid serum per milliliter $(\mu \mathrm{leq} / \mathrm{ml})$. This assay is sensitive and reproducible and has proved to be an excellent tool for evaluation of patients with para-
TABLE I

The Incidence of Various Complications of Pregnancy and the Neonatal Period in Sick and Hypocalcemic Infants

\begin{tabular}{lcc}
\hline & $\begin{array}{c}\text { Sick } \\
\text { infants } \\
(n=55)\end{array}$ & $\begin{array}{c}\text { Hypocalcemic } \\
\text { infants } \\
(n=43)\end{array}$ \\
\hline Prematurity & $\%$ & $\%$ \\
Cesarean section & 38 & 47 \\
Maternal diabetes & 25 & 44 \\
Asphyxia & 16 & 21 \\
Respiratory distress & 14 & 19 \\
$\quad$ syndrome & 11 & \\
Hyperbilirubinemia & 15 & 14 \\
Placental abnormalities & 2 & 19 \\
Sepsis & 16 & 7 \\
\end{tabular}

thyroid disorders. Its lower limit of sensitivity is $2 \mu$ leq/ ml. Approximately $75 \%$ of normal older children and adults have detectable levels of serum iPTH with this assay, with an upper limit of $10 \mu \mathrm{leq} / \mathrm{ml}$. Plasma $\mathrm{Ca}$ and $\mathrm{Mg}$ levels were determined by atomic absorption spectrophotometry (Perkin-Elmer Corp., Instrument Div., Norwalk, Conn.) (10), plasma $\mathrm{Ca}^{++}$levels with the Orion flow-through electrode (Model 88-20) (Orion Research, Inc., Cambridge, Mass.) (11), and plasma inorganic phosphorus (P) levels by the method of Fiske and Subbarow (12) adapted to the Technicon autoanalyzer (Technicon Instruments Corp., Tarrytown, N. Y.).

Statistical analysis. There was insufficient evidence to justify the assumption that the underlying distributions were normal. For that reason nonparametric tests were used. Differences in plasma $\mathrm{Ca}^{++}, \mathrm{Ca}, \mathrm{Mg}, \mathrm{P}$, and serum iPTH levels during the various time periods and comparisons between the corresponding data obtained in the different groups of newborns were analyzed with the Wi1coxon tests (13). When both individual and serial values were available to compare data from different time periods, the data were analyzed separately by the appropriate test of Wilcoxon (i.e., two samples rank sum test for the individual values and matched pairs signed ranks test for the serial values); the independent tests of significance were then combined by the technique described by Stautler (14). Spearman's rank correlation test (13) was used for correlation analysis. $P$ values less than 0.05 were considered as significant in all of the tests.

\section{RESULTS}

Normal group (Fig. 1). The mean \pm SD values of plasma $\mathrm{Ca}^{++}, \mathrm{Ca}, \mathrm{Mg}$, and $\mathrm{P}$ were calculated from individual or serial determinations obtained in 137 newborn infants from birth (cord blood) to $158 \mathrm{~h}$ of age. A total of 187 serum iPTH determinations were made in 89 of the 137 infants; thus, serial determinations were made in many infants, while inadequate volume of serum samples prevented us from determining serum iPTH levels in other infants. In Fig. 1, as well as in Figs. 2 and 3 , each dot represents a single value on an individual patient. 


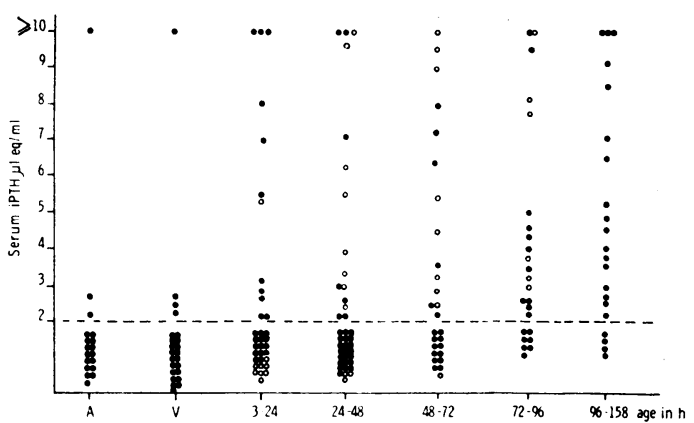

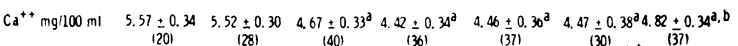

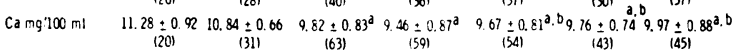

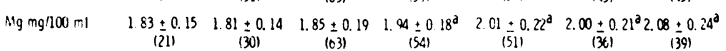

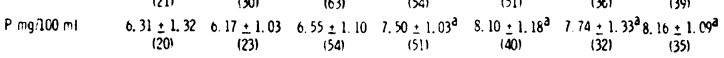

FIgURE 1 Serum iPTH levels and mean \pm SD of plasma $\mathrm{Ca}^{++}, \mathrm{Ca}, \mathrm{Mg}$, and $\mathrm{P}$ levels in normal newborn infants. The interrupted line indicates the limit of detectability of the assay. The numbers in parentheses correspond to the number of values available for the calculation of the corresponding means. Each dot represents a single value on an individual patient. $\bigcirc$ indicates values previously reported (2). A : arterial cord blood. V: venous cord blood.

a Significantly different $(P<0.01)$ from the venous cord blood value.

bignificantly different $(P<0.01)$ from the $24-48$-h value.

In the cord blood no significant differences were observed between any of the arterial and venous values. However, the mean plasma $\mathrm{Ca}$ and $\mathrm{Ca}^{++}$were significantly higher and the mean plasma $\mathrm{Mg}$ was significantly lower in cord blood when compared to corresponding values obtained in older infants and children. ${ }^{2}$ The mean plasma $\mathrm{P}$ level in cord blood was higher than that usually found in older infants and children, but a wide range of values was observed $(3.85-9.00 \mathrm{mg} / 100 \mathrm{ml})$. Except for one infant, the serum iPTH levels in cord blood were undetectable $(83 \%)$ to low. In the one in-

The older infants and children consisted of 165 normal subjects, ranging in age from 1 mo to $15 \mathrm{yr}$, seen in the Department of Pediatrics at the University of Missouri Medical Center. The mean \pm SD plasma values of this normal group of children were: $\mathrm{Ca}^{++}, 4.52 \pm 0.33 \mathrm{mg} / 100 \mathrm{ml}$; $\mathrm{Ca}, 9.95 \pm 0.48 \mathrm{mg} / 100 \mathrm{ml} ; \mathrm{Mg}, 2.07 \pm 0.19 \mathrm{mg} / 100 \mathrm{ml}$; and $\mathrm{P}, 4.66 \pm 0.82 \mathrm{mg} / 100 \mathrm{ml}$. When analyzed at $3-\mathrm{yr}$ intervals there was little variation in the $\mathrm{Ca}^{++}, \mathrm{Ca}$, and $\mathrm{Mg}$ in the various age groups studied. The plasma $P$ level in the normal children showed a progressive decline from 5.75 $\pm 0.91 \mathrm{mg} / 100 \mathrm{ml}$ in the age group $1 \mathrm{mo}-3 \mathrm{yr}$ to $4.14 \pm 0.71$ $\mathrm{mg} / 100 \mathrm{ml}$ in the age group 12-15 yr. Serum iPTH levels in this group of normal children ranged from undetectable to $10 \mu \mathrm{leq} / \mathrm{ml}$, with $27 \%$ of the levels being undetectable. Excellent differentiation is observed with this assay between patients with primary hyperparathyroidism and normal subjects. The level of serum iPTH has been found to be above the normal range in over $95 \%$ of patients with primary hyperparathyroidism, while undetectable levels have been a constant finding in hypoparathyroid patients (6). fant the values for the arterial and venous cord blood were 37 and $33 \mu$ leq $/ \mathrm{ml}$, respectively.

A significant fall in plasma $\mathrm{Ca}^{++}$and $\mathrm{Ca}$ was observed in the normal newborns during the first $48 \mathrm{~h}$ of life; this was followed by a rise in plasma $\mathrm{Ca}^{++}$and $\mathrm{Ca}$ after $48 \mathrm{~h}$ of age. The mean plasma $\mathrm{Mg}$ level increased progressively from $1.81 \pm 0.14 \mathrm{mg} / 100 \mathrm{ml}$ in venous cord blood to $2.08 \pm 0.24 \mathrm{mg} / 100 \mathrm{ml}$ between 96 and $158 \mathrm{~h}$ of life. The mean plasma $P$ levels for each of the time periods studied after $24 \mathrm{~h}$ of age were significantly higher than the mean values found in cord blood and before $24 \mathrm{~h}$ of age. Though the mean value between 3 and $24 \mathrm{~h}$ of age was higher than cord blood, the difference was not significant.

In the majority of normal newborn infants the serum iPTH levels were undetectable or low during the first $48 \mathrm{~h}$ of life. Only $36 \%$ of the serum iPTH levels were detectable before $48 \mathrm{~h}$ of age. Subsequently, an increase in serum iPTH was observed so that after $72 \mathrm{~h}$ of life, $76 \%$ of the values were detectable.

Elevated serum iPTH levels above $10 \mu \mathrm{leq} / \mathrm{ml}$ were found in 12 instances and were equally distributed among the time periods studied. In five instances the values were moderately high, ranging from 12 to $23 \mu \mathrm{leq} / \mathrm{ml}$. The remaining seven elevated values were all above 30 $\mu \mathrm{leq} / \mathrm{ml}$ and were observed in serial studies of three infants who included the previously mentioned infant with elevated cord blood iPTH values. The serial values were relatively constant in each of these infants; i.e., values of serum iPTH of 79,79 , and $74 \mu \mathrm{leq} / \mathrm{ml}$ were observed at 21,45 , and $79 \mathrm{~h}$ of age, respectively, in one infant, while values of 34 and $32 \mu \mathrm{leq} / \mathrm{ml}$ were observed at 18 and $38 \mathrm{~h}$, respectively, in another infant. Similarly, in the infant who had high levels of cord blood iPTH, values of 71 and $68 \mu \mathrm{leq} / \mathrm{ml}$ were found at 25 and $100 \mathrm{~h}$ of age, respectively. The possibility that the elevated levels might, in part at least, be artifactual and the result of nonspecific serum factors will be discussed later.

Among the 36 newborns in whom determinations of serum iPTH were made before and after $48 \mathrm{~h}$ of age, the values increased in 23 and decreased in 5 , while no demonstrable change was observed in 8 (in 6 the values remained undetectable).

Sick group (Fig. 2). Though the plasma Ca levels were above $7.5 \mathrm{mg} / 100 \mathrm{ml}$ in all of the sick infants, the mean plasma $\mathrm{Ca}^{++}$and $\mathrm{Ca}$ were lower than in the normal group. No significant differences in the plasma $\mathrm{Ca}^{++}$and $\mathrm{Ca}$ levels were found in the sick infants in the various time periods studied.

The plasma $\mathrm{Mg}$ levels in the sick infants were not significantly different from those in the normal infants and showed the same trend of a progressive rise during the time periods studied. The serum $P$ levels were significantly lower in the sick infants when compared with 


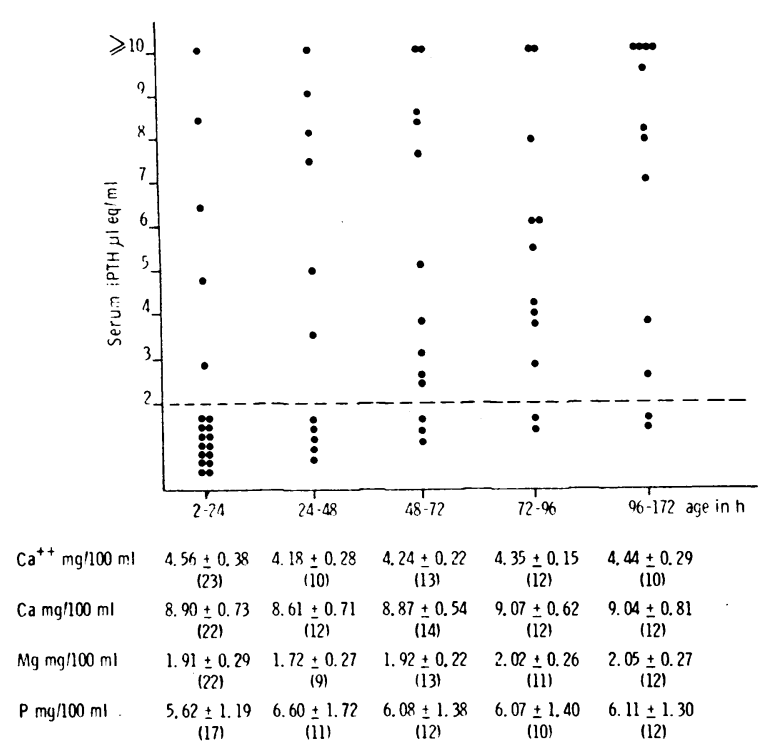

Figure 2 Serum iPTH levels and mean \pm SD of plasma $\mathrm{Ca}^{++}, \mathrm{Ca}, \mathrm{Mg}$, and $\mathrm{P}$ levels in sick newborn infants. The interrupted line indicates the limit of detectability of the assay. No significant differences $(P>0.05)$ were found between the plasma $\mathrm{Ca}^{++}, \mathrm{Ca}, \mathrm{Mg}$, or $\mathrm{P}$ levels at different time periods.

the normal group in each of the time intervals studied $(P<0.01)$.

The general pattern of serum iPTH levels in the sick neonates was similar to that observed in the normal group and no statistical differences were found during each of the time periods studied. As in the normal group, only $36 \%$ of the serum iPTH levels were detectable before $48 \mathrm{~h}$, with an increase to $83 \%$ being observed after $72 \mathrm{~h}$ of age. However, the increase in serum iPTH occurred earlier in the sick group, as demonstrated by the finding of 56 and $77 \%$ detectable levels at $24-48$ and 48-72 h, respectively, as compared to 37 and $51 \%$ in the normal group. Furthermore, the percentage of serum iPTH levels in the mid to high-normal range was greater in the sick than in the normal group, particularly during the time periods $72-96 \mathrm{~h}$ and after $96 \mathrm{~h}$, when 50 and $66 \%$, respectively, had levels higher than $5 \mu \mathrm{leq} / \mathrm{ml}$ in the sick infants compared to 25 and $38 \%$ in the normal infants. Nine of the 55 sick infants had serum iPTH levels greater than $10 \mu \mathrm{leq} / \mathrm{ml}$; six of them had moderately elevated values ranging from 11.5 to $25 \mu \mathrm{leq} / \mathrm{ml}$; while the values in the other three infants were 36,54 , and $115 \mu \mathrm{leq} / \mathrm{ml}$.

Hypocalcemic group (Fig. 3). There is no agreement in the literature concerning the level of plasma $\mathrm{Ca}$ which defines neonatal hypocalcemia. Authors have variously defined neonatal hypocalcemia as a plasma $\mathrm{Ca}$ level less than $8 \mathrm{mg} / 100 \mathrm{ml}$ (15), less than $7.5 \mathrm{mg} / 100$ $\mathrm{ml}$ (16), or less than $7 \mathrm{mg} / 100 \mathrm{ml}$ (17). In our study, neonatal hypocalcemia was defined as a plasma $\mathrm{Ca}$ level less than $7.5 \mathrm{mg} / 100 \mathrm{ml}$; this value corresponds to approximately $2 \mathrm{SD}$ below the lowest mean plasma $\mathrm{Ca}$ level observed in our normal newborns. The plasma $\mathrm{Ca}^{++}$levels were lower than $4 \mathrm{mg} / 100 \mathrm{ml}$ in all of the infants in this group.

Between 5 and $24 \mathrm{~h}$ of age the mean plasma $\mathrm{Mg}$ level of the hypocalcemic infants was similar to that of the normal and sick infants. However, after $24 \mathrm{~h}$ of age the mean plasma $\mathrm{Mg}$ levels were consistently lower in the hypocalcemic infants than in the normal $(P<0.01$ in each time interval) or sick $(P<0.05$ in each time interval) infants. The relationship between the plasma $\mathrm{Mg}$ levels in the normal, sick, and hypocalcemic infants is shown in Fig. 4.

A wide range of plasma $\mathrm{P}$ was observed during each of the time periods and, although the mean values were generally lower than the corresponding values in the normal group, the differences were not statistically significant, nor were there any significant differences between the plasma $P$ levels in the hypocalcemic and sick infants. The relationship between the plasma $P$ levels in the normal, sick, and hypocalcemic infants is shown in Fig. 4. It is important to point out that hyperphosphatemia was not a common finding in the infants with hypocalcemia. Only 6 of the 43 hypocalcemic infants had plasma $\mathrm{P}$ levels greater than one standard deviation above the mean values of the normal group.

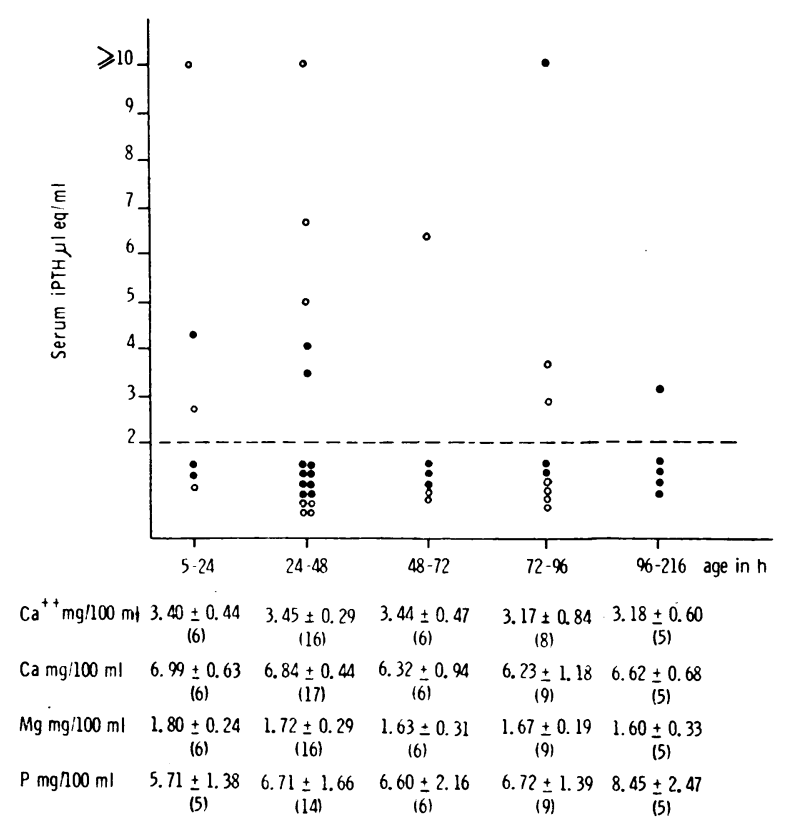

Figure 3 Serum iPTH levels and mean \pm SD of plasma $\mathrm{Ca}^{++}, \mathrm{Ca}, \mathrm{Mg}$, and $\mathrm{P}$ levels in hypocalcemic infants. The interrupted line indicates the limit of detectability of the assay. No significant differences $(P>0.05)$ were found between the plasma $\mathrm{Ca}^{++}, \mathrm{Ca}, \mathrm{Mg}$, or $\mathrm{P}$ levels at different time periods. $\bigcirc$ indicates values previously reported (2). 

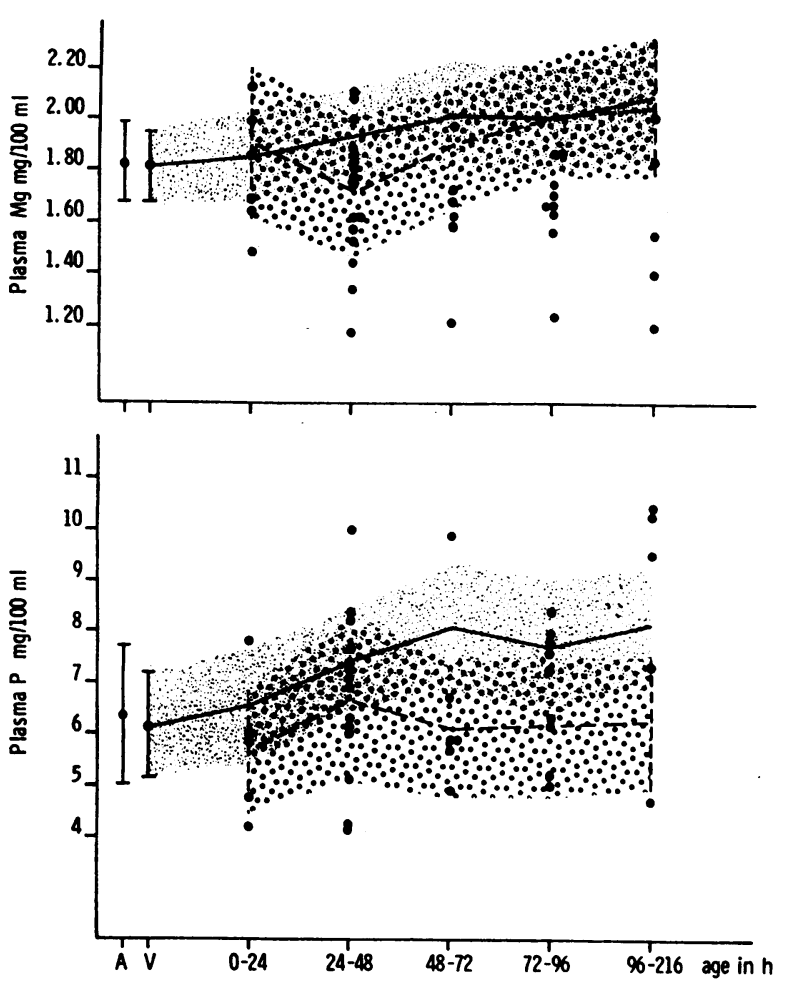

Figure 4 Comparison of plasma $\mathrm{Mg}$ and $\mathrm{P}$ levels in normal, sick, and hypocalcemic newborn infants. The shaded area indicates the $\pm S D$ of mean values of the normal infants. The stippled area indicates the $\pm S D$ of mean values of the sick infants. Solid circles indicate individual values of the hypocalcemic infants. A : arterial cord blood. $\mathrm{V}$ : venous cord blood.

The great majority $(88 \%)$ of the serum iPTH values determined in the hypocalcemic infants were undetectable or in the low to mid-normal range. In contrast to the normal and sick infants, depressed serum iPTH values were found before as well as after $48-72 \mathrm{~h}$ of life in the hypocalcemic group. Serum iPTH was detectable in $35 \%$ of hypocalcemic infants before $48 \mathrm{~h}$ of age and in only $28 \%$ after $72 \mathrm{~h}$ of age. Only 3 of 43 infants had elevated levels of serum iPTH $(16,30$, and $37.5 \mu \mathrm{leq} / \mathrm{ml})$ in the presence of hypocalcemia. This is in contrast to the consistently elevated levels of serum iPTH that we have observed in older infants and children with hypocalcemia due to a variety of causes other than parathyroid insufficiency.

Summary of comparative findings in normal, sick, and hypocalcemic infants. The serum iPTH levels were usually undetectable or low in cord blood as well as during the first $48 \mathrm{~h}$ of life in normal, sick, and hypocalcemic infants. After $48-72 \mathrm{~h}$ of life an increase in serum iPTH was observed in the normal and sick infants, but not in the hypocalcemic infants. A study of the incidence of detectable plasma iPTH levels during the first 7-9 days of life provides a comparative indi- cator of the pattern of parathyroid activity in the three groups. During the first $48 \mathrm{~h}$ of life the serum iPTH levels were detectable in approximately $35-36 \%$ of infants in each of the three groups, i.e., normal, sick, and hypocalcemic. After $72 \mathrm{~h}$ of life the percentage of detectable serum iPTH levels was 75 in the normal infants, 83 in the sick infants, and 28 in the hypocalcemic infants. There was a tendency for the increase in serum iPTH to occur earlier, and for the iPTH levels to be higher in the sick infants than in the normal infants.

The plasma $\mathrm{Ca}$ and $\mathrm{Ca}^{++}$were elevated in cord blood. In normal infants the $\mathrm{Ca}$ and $\mathrm{Ca}^{++}$levels fell during the first $48 \mathrm{~h}$ of life and then rose after $48 \mathrm{~h}$ of life, paralleling the rise in serum iPTH. By definition the plasma total calcium was less than $7.5 \mathrm{mg} / 100 \mathrm{ml}$ in the hypocalcemic infants. Though the plasma $\mathrm{Ca}$ levels were above $7.5 \mathrm{mg} / 100 \mathrm{ml}$ in all of the sick infants, the mean plasma $\mathrm{Ca}^{++}$and $\mathrm{Ca}$ were significantly lower than in the normal group. No significant differences in the plasma $\mathrm{Ca}^{++}$and $\mathrm{Ca}$ levels were found in the sick infants in the various time periods studied.

A progressive increase in plasma $\mathrm{Mg}$ was observed in normal newborn infants during the first week of life. The plasma $\mathrm{Mg}$ levels in the sick infants were not significantly different from those in the normal infants and showed the same trend of a progressive rise during the first week of life. By contrast, after $24 \mathrm{~h}$ of age the mean plasma $\mathrm{Mg}$ levels were consistently and significantly lower in the hypocalcemic infants than in the normal and sick infants.

In the normal newborn infants the plasma $\mathrm{P}$ levels were significantly higher after $24 \mathrm{~h}$ of age than before $24 \mathrm{~h}$ of age. The plasma $\mathrm{P}$ levels in the sick infants were significantly lower than those of the normal infants in each of the time periods studied. A wide range of plasma $\mathrm{P}$ was observed in the hypocalcemic infants in each of the time periods studied and, although the mean values were generally lower than the corresponding values in the normal group, the differences were not statistically significant. It is important to point out that hyperphosphatemia was an uncommon finding in the infants with hypocalcemia.

Correlation analysis. In the normal infants plasma $\mathrm{Ca}^{++}$and $\mathrm{Ca}$ levels were significantly correlated $(P<$ 0.05 ) in the cord blood and from $24 \mathrm{~h}$ to $158 \mathrm{~h}$, while no correlation was found from 3 to $24 \mathrm{~h}$. Plasma $\mathrm{Ca}^{++}$ and $\mathrm{Ca}$ levels were not correlated at any time in the sick and hypocalcemic infants. Serum iPTH levels did not correlate in any of the three groups of infants with plasma $\mathrm{Ca}^{++}, \mathrm{Ca}, \mathrm{Mg}$, or $\mathrm{P}$ levels. No correlations were observed between plasma $\mathrm{Ca}^{++}$or $\mathrm{Ca}$ levels and plasma $\mathrm{P}$ levels. There was a significant positive correlation between plasma $\mathrm{Ca}$ levels and plasma $\mathrm{Mg}$ levels in the normal group and in the sick group from 72 to $96 \mathrm{~h}(P<$ 
0.05 and after $96 \mathrm{~h}(P<0.01)$, while in the hypocalcemic group a significant positive correlation was found only between 72 and $96 \mathrm{~h}(P<0.05)$. Because $38 \%$ of the sick and $47 \%$ of the hypocalcemic infants were premature, we analyzed the gestational age in these two groups of infants in relationship to the plasma $\mathrm{Ca}^{++}$, plasma $\mathrm{Ca}$, and serum iPTH levels, but no significant correlations were found at any time.

\section{DISCUSSION}

The finding reported in this paper of undetectable iPTH levels in the cord blood of most of the infants studied indicates that parathyroid secretion is depressed at birth. The corollary to this observation is that the high levels of plasma $\mathrm{Ca}$ and $\mathrm{Ca}^{++}$present in cord blood are not the result of hyperactivity of the fetal parathyroid glands. This places greater emphasis on the primordial role of the placenta in maintaining a high fetal-to-maternal calcium gradient by means of a specific calcium active transport mechanism (18). It seems reasonable to hypothesize that the relatively high plasma $\mathrm{Ca}$ levels induced by the placental calcium pump contribute to the depression of fetal and neonatal parathyroid function.

In view of the results of our cord blood studies, it is pertinent to briefly review previously published work, in which attempts were made by a variety of means to assess parathyroid function during embryonic life in humans and experimental animals. Histologic studies indicate that fetal human parathyroid glands at midpregnancy have the typical features of active adult glands, including the presence of vesicular cells (19, $20)$. In vitro studies strongly suggest that in the first third of gestation secretory activity is present in human, sheep, guinea pig, and chicken fetal parathyroid glands, as indicated by the ability of the glands to induce bone resorption when explanted in close contact with neonatal rat parietal bone (21-23). Further evidence for the presence of circulating parathyroid hormone in the fetus is that a fall in plasma $\mathrm{Ca}$ occurs in the rat fetus after thyroparathyrodectomy or the injection of antibovine parathyroid hormone $(24,25)$. More direct evidence for active fetal parathyroid function was obtained by Smith, Alexander, Buckle, Britton, and Nixon (26), who demonstrated increased levels of serum iPTH in five sheep fetuses during the last half of pregnancy in response to EDTA-induced hypocalcemia.

The foregoing evidence of fetal parathyroid activity appears to be inconsistent with the large number of undetectable serum iPTH levels found in cord blood in our study. However, it should be recognized that many of the previously reported results were obtained from studies of fetuses during the first half of gestation and therefore cannot be directly applied to the status of the parathyroid glands at the end of pregnancy. Indeed, im- portant changes in calcium homeostasis occur in both the mother and fetus during gestation. In human studies it has been demonstrated that plasma $\mathrm{Ca}^{++}$and $\mathrm{Ca}$ levels decrease (27) while the serum iPTH increases (28) during the last trimester of pregnancy. In the guinea pig and rabbit the fetal plasma $\mathrm{Ca}$ level decreases significantly below the maternal level at approximately mid-gestation, corresponding in the time with the onset of fetal skeletal calcification; subsequently, the fetal plasma $\mathrm{Ca}$ concentration increases and exceeds the maternal level at the end of gestation $(29,30)$. In this regard, the findings of Smith et al. are important and pertinent to the discussion (26). They found undetectable basal values of plasma iPTH in three of four sheep fetuses.with high $\mathrm{Ca}$ levels during the late stage of gestation, while a fifth fetus at mid-gestation had relatively lower basal $\mathrm{Ca}$ levels and a detectable level of iPTH. Thus, the finding of high plasma calcium levels and undetectable iPTH levels in sheep fetuses late in gestation is consistent with our findings in the cord blood of newborn infants at birth.

The persistence of undetectable to low serum iPTH levels while the plasma $\mathrm{Ca}^{++}$and $\mathrm{Ca}$ fall during the first $48 \mathrm{~h}$ of life in normal newborns and the subsequent parallel increases in iPTH, $\mathrm{Ca}^{++}$, and $\mathrm{Ca}$ levels suggest that neonatal parathyroid function remains depressed for a short period of time after birth. The increase in parathyroid activity observed in normal newborns after $48 \mathrm{~h}$ of life is consistent with the increase in phosphate clearance $(31,32)$ and in urinary cyclic AMP (32) that has been reported between the first and third day of life in normal newborn infants.

The major finding in the hypocalcemic group was the prevalence of undetectable or inappropriately low serum iPTH levels before as well as after $48 \mathrm{~h}$ of age. This is in sharp contrast to the consistently elevated levels of serum iPTH observed in our laboratory in older hypocalcemic infants and children with intact parathyroid function. Thus, evidence obtained from our study demonstrates that neonatal hypocalcemia is frequently associated with impaired parathyroid function.

It is of interest that though the majority of normal and sick newborn infants had undetectable levels of serum iPTH before $48 \mathrm{~h}$ of age, the fall in plasma $\mathrm{Ca}^{++}$ and $\mathrm{Ca}$ in these infants was relatively small when compared to the hypocalcemic group. The reason for this is not clear. After $48 \mathrm{~h}$ of age, differences in parathyroid function are more apparent since the majority of normal and sick infants had detectable levels of serum iPTH while the majority of hypocalcemic infants had undetectable levels. Thus, the studies of infants older than $48 \mathrm{~h}$ more clearly demonstrated the association of parathyroid insufficiency and neonatal hypocalcemia.

The importance of taking the age of the neonates into 
consideration in evaluating parathyroid function was also demonstrated in studies of infants undergoing exchange transfusions previously reported by our laboratory (2). Base-line plasma $\mathrm{Ca}^{++}$levels were within the normal range in these infants but, because of the citrate in the donor's blood, plasma $\mathrm{Ca}^{++}$decreased markedly in all infants during exchange transfusion, giving us the unique opportunity to assess the response of the neonatal parathyroid glands to acute hypocalcemic stress. We observed that infants older than $48 \mathrm{~h}$ responded to acute hypocalcemia induced by exchange transfusion with a distinct increase in circulating $\mathrm{iPTH}$, while in younger infants the response was either poor or absent.

The exchange transfusion studies demonstrated that impaired parathyroid responsiveness to acute hypocalcemia is a common finding in nonhypocalcemic infants in the first $24-48 \mathrm{~h}$ of life and that after $48 \mathrm{~h}$, the parathyroid glands are able to respond appropriately to hypocalcemia. This finding is consistent with the spontaneous rise in serum iPTH observed after $48 \mathrm{~h}$ in normal infants. Thus, the exchange transfusion studies lend support to the present study and further demonstrate that the presence of low and undetectable levels of iPTH in hypocalcemic infants older than $48 \mathrm{~h}$ is of pathologic significance.

In each group of newborns studied, a small number of infants had elevated serum iPTH levels. The significance of this finding is uncertain. It is possible that, in some cases at least, the apparent high levels were artifactual, due to nonspecific factors that may influence immunoassay procedures rather than to elevated serum iPTH. Evidence in favor of this possibility is the relatively even distribution of high serum iPTH values in each group of newborns and in each time period studied. Unfortunately the small amount of serum available from the newborns did not give us the opportunity to carry out studies to differentiate between true iPTH and nonspecific factors. On the other hand, it is possible that factors other than parathyroid insufficiency might act in the newborn period to reduce plasma $\mathrm{Ca}$ so that in some neonates, elevated circulating parathormone levels would be required to maintain calcium homeostasis. Thus, in some infants the compensatory increase in parathyroid activity would be sufficient to maintain the plasma $\mathrm{Ca}$ level in the normal range, while in other infants there would either be no compensatory increase because of parathyroid unresponsiveness, or the compensatory increase would be insufficient and hypocalcemia would result. Several nonparathyroid factors have been mentioned in the past as possibly being involved in the pathogenesis of neonatal hypocalcemia. These include hyperphosphatemia, disturbances in vitamin $\mathrm{D}$ metabolism, hypercalcitonin secretion, and elevated circulating adrenocorticosteroid hormones. However, no direct evi- dence has been presented to implicate any of these factors.

It is well known that hypocalcemia frequently occurs in newborn infants who are sick and/or the products of abnormal pregnancies and labors. This was true in our study and suggests that the hypocalcemic factor(s) might in some way be related to perinatal pathology. The net effects of unknown serum hypocalcemic factor (s) on the one hand and parathyroid activity on the other may account for the differences in plasma $\mathrm{Ca}$ levels observed between normal, sick, and hypocalcemic infants. Indeed, it is possible that in the sick infants, a compensatory parathyroid response prevented a more pronounced fall in plasma $\mathrm{Ca}$ to hypocalcemic levels; in this regard the tendency toward higher serum iPTH levels in the sick group as compared to the normal group may be of significance.

As indicated previously, hyperphosphatemia has been implicated as a possible etiologic factor in neonatal hypocalcemia. Neonatal hyperphosphatemia has variously been attributed to renal immaturity, dietary phosphorus load, excessive tissue breakdown, and transient hypoparathyroidism. Tsang, Kleinman, Sutherland, and Light (33) observed a significant negative correlation between plasma $\mathrm{P}$ and $\mathrm{Ca}$ levels in the cord blood and at $24 \mathrm{~h}$, but not at $48 \mathrm{~h}$ of age in a group of 20 newborns of diabetic mothers. In another study Tsang and $\mathrm{Oh}$ (17) found that hypocalcemic low birth-weight infants had significantly higher values of plasma $P$ than nonhypocalcemic low birth-weight infants at 8 and $29 \mathrm{~h}$ of age. However, in other reports $(15,16,34,35)$ no correlation was found between the plasma $\mathrm{Ca}$ and $\mathrm{P}$ levels in normal and hypocalcemic newborns. In our study we did not find any correlation between the plasma $\mathrm{Ca}$ and $P$ levels in the normal, sick, or hypocalcemic newborns. Many hypocalcemic infants had relatively low levels of plasma $P$, and only 6 of the 43 hypocalcemic infants had elevated plasma P. Thus, in the majority of the hypocalcemic infants, there was no evidence that hyperphosphatemia played a contributory role in the pathogenesis of the hypocalcemia. The fact that three of the five hypocalcemic infants older than $96 \mathrm{~h}$ had elevated plasma $\mathrm{P}$ levels and undetectable serum iPTH levels suggests that, in part at least, the hyperphosphatemia was secondary to hypoparathyroidism. It is not clear why the sick group had lower levels of plasma $P$ than the normal group and did not demonstrate a rise in plasma $P$ levels as did the normal infants. It is of interest that Radde, Parkinson, Hoffken, Apiah, and Hanley (36) made a similar observation in a group of sick infants. A possible explanation is that, due to poor feeding, the dietary intake of $\mathrm{P}$ was less in the sick infants than in the normal group. This may also account for the rela- 
tively low plasma $\mathrm{P}$ levels found in many of the hypocalcemic infants.

The importance of magnesium in the pathogenesis of hypocalcemia has become evident in the last decade, with numerous reports of an association between hypomagnesemia and hypocalcemia $(3,4,37-40)$. The published reports indicate that magnesium deficiency may interfere with normal parathyroid function, either by impairing the secretion and/or synthesis of the hormone $(3,4)$ or by interfering with the action of the hormone at the target organs (39). In our study, depressed plasma $\mathrm{Mg}$ was a frequent finding in hypocalcemic infants.

Newborn infants with depressed plasma $\mathrm{Mg}$ may be divided into two groups (41): (a) chronic congenital low plasma $\mathrm{Mg}$ or "primary hypomagnesemia with secondary hypocalcemia," and (b) transient low plasma $\mathrm{Mg}$.

Chronic congenital hypomagnesemia with secondary hypocalcemia appears to be a relatively rare disease due to a primary defect in the gastrointestinal absorption of magnesium. The serum magnesium is usually less than $1.0 \mathrm{mg} / 100 \mathrm{ml}$ and frequently is in the range of $0.4-0.8$ $\mathrm{mg} / 100 \mathrm{ml}$. Hypomagnesemia in this disorder appears to lead to impaired synthesis and/pr secretion of parathyroid hormone, which is alleviated by magnesium therapy $(3,4)$. Relapses occur without continuous magnesium supplements.

In infants with transient hypomagnesemia the serum $\mathrm{Mg}$ level is usually higher than in infants with primary chronic hypomagnesemia, frequently ranging from 0.8 to $1.4 \mathrm{mg} / 100 \mathrm{ml}$. Depressed plasma $\mathrm{Ca}$ frequently, but not always, accompanies transient hypomagnesemia. Magnesium therapy is usually not required in infants with transient hypomagnesemia, since the plasma $\mathbf{M g}$ increases spontaneously as the plasma $\mathrm{Ca}$ returns to normal after the administration of calcium supplements. However, in some cases the hypocalcemia responds poorly to calcium therapy, but after treatment with magnesium salts, the plasma $\mathrm{Ca}$ as well as plasma $\mathrm{Mg}$ rise. In contrast to infants with chronic primary hypomagnesemia, only a short course of magnesium therapy is needed and relapses do not occur.

In our study plasma $\mathrm{Mg}$ levels were significantly lower in the hypocalcemic infants when compared to normal and sick neonates. After $24 \mathrm{~h}$ of age the mean plasma $\mathrm{Mg}$ in normal newborn infants ranged from 1.94 to 2.08 $\mathrm{mg} / 100 \mathrm{ml}$; by contrast the mean plasma $\mathrm{Mg}$ in the hypocalcemic infants was approximately $1.65 \mathrm{mg} / 100 \mathrm{ml}$ and approximately $20 \%$ of the hypocalcemic infants had plasma $\mathrm{Mg}$ levels that ranged between 1.17 and 1.50 $\mathrm{mg} / 100 \mathrm{ml}$. Magnesium therapy was not required to correct the hypocalcemia, and the plasma $\mathrm{Mg}$ increased spontaneously as the plasma $\mathrm{Ca}$ returned to normal. The reason for the depressed $\mathrm{Mg}$ in infants with transi- ent hypomagnesemia is unknown. It is possible that extracellular $\mathrm{Mg}$ is subjected to the same physiological and pathological influences as $\mathrm{Ca}$ during the neonatal period. Low plasma $\mathrm{Mg}$ levels have been observed in hypoparathyroid subjects (42), and it is possible that depressed plasma $\mathrm{Mg}$ in many hypocalcemic newborns is a manifestation of parathyroid insufficiency. On the other hand, it is possible that transient hypomagnesemia, in some infants at least, is due to nonparathyroid factors and that the hypomagnesemia contributes to the hypocalcemia by impairing parathyroid function, as has been demonstrated in infants with primary hypomagnesemia. If this were the case, then $\mathrm{Mg}$ supplements or conceivably the $\mathrm{Mg}$ in milk formulas received by the infants could alleviate the hypomagnesemia and restore parathyroid function to normal. In comparison to infants with primary hypomagnesemia, however, the plasma $\mathrm{Mg}$ was only moderately reduced in our infants with transient hypomagnesemia. Whether or not this moderate reduction in plasma $\mathrm{Mg}$ can impair parathyroid function is unknown and currently under investigation.

\section{ACKNOWLEDGMENTS}

The authors gratefully acknowledge the technical assistance of Ms. Sammy Langeluttig, Dr. Arsenia Rodriguez, Ms. Marcia Schweiss, Ms. Mary Thomas, and Mr. David Lionberger. Dr. John Hewett and Dr. Gerald Chase from the Department of Statistics, University of Missouri, have given invaluable assistance in the statistical analysis of the data. The authors are very appreciative of the cooperation and kindness extended to them by the personnel of the Newborn Nursery at the University of Missouri Medical Center, especially Dr. Elizabeth James, Dr. Larry Johnsgard, and Ms. Sharon King, R.N. We extend our thanks to Ms. Fern McClanahan and Ms. Alda Hyatt for their expert help in preparation of the manuscript.

This work was supported by Public Health Research Grant HD-02756 and AM-01351.

\section{REFERENCES}

1. Anast, C. S. 1969. Tetany of the newborn. In Endocrine and Genetic Diseases of Childhood. L. Gardner, editor. W. B. Saunders Company, Philadelphia. 352.

2. David, L., and C. S. Anast. Evaluation of parathyroid function in newborns. In Clinical Aspects of Metabolic Bone disease. B. Frame, A. M. Parfitt, and H. Duncan, editors. Excerpta Medica Foundation, Publishers, Amsterdam. 661-666.

3. Anast, C. S., J. M. Mohs, S. L. Kaplan, and T. W. Burns. 1972. Evidence for parathyroid failure in magnesium deficiency. Science (Wash. D. C.). 177: 606608.

4. Suh, S. M., A. H. Tashjian, Jr., N. Matsuo, D. K. Parkinson, and D. Fraser. 1973. Pathogenesis of hypocalcemia in primary hypomagnesemia: normal endorgan responsiveness to parathyroid hormone. Impaired parathyroid gland function. J. Clin. Invest. 52: 
5. Dubowitz, L. M. S., V. Dubowitz, and C. Goldberg. 1970. Clinical assessment of gestational age in the newborn infant. J. Pediatr. 77: 1-10.

6. Conaway, H. H., and C. S. Anast. 1974. Double-antibody immunoassay for parathyroid hormone: J. Lab. Clin. Med. 83 : 129-138.

7. Canterbury, J. M., and E. Reiss. 1972. Multiple immunoreactive molecular forms of parathyroid hormone in serum. Proc. Soc. Exp. Biol. Med. 140: 1393-1398.

8. Habener, J. F., D. Powell, T. M. Murray, G. P. Mayer, and J. T. Potts, Jr. 1971. Parathyroid hormone: secretion and metabolism in vivo. Proc. $N^{\top}$ atl. Acad. Sci. U. S. A. 68: 2986-2991.

9. Goldsmith, R. S., J. Furszyfer, W. J. Johnson, A. E. Fournier, G. W. Sizemore, and C. D. Arnaud. 1973. Etiology of hyperparathyroidism and bone disease during chronic hemodialysis. III. Evaluation of parathyroid suppressibility. J. Clin. Invest. 52: 173-180.

10. Slavin, W. 1968. Atomic absorption spectroscopy. John Wiley and Sons, Inc., New York.

11. Moore, E. W. 1970. Ionized calcium in normal serum, ultrafiltrates, and whole blood determined by ionexchange electrodes. J. Clin. Invest. 49: 318-334.

12. Fiske, C. H., and Y. Subbarow. 1925. Colorimetric determination of phosphorus. J. Biol. Chem. 66: 375-400.

13. Snedecor, G. W., and W. G. Cochran. 1967. Statistical Methods. Iowa State University Press, Ames, Iowa. 6th edition. 120-134.

14. Moses, L. E. 1956. Statistical theory and research design. Annu. Rev. Psychol. 7 : 233-244.

15. Gittleman, I. F., E. Schmerler, M. Saito, and J. B. Pincus. 1956. Hypocalcemia in the newborn. Pediatrics. 18: 721-729.

16. Keen, J. H. 1969. Significance of hypocalcaemia in neonatal convulsions. Arch. Dis. Child. 44: 356-361.

17. Tsang, R. C., and W. Oh. 1970. Neonatal hypocalcemia in low birth weight infants. Pediatrics. 45: 773-781.

18. Shami, Y., and I. C. Radde. 1971. Calcium-stimulated ATPase of guinea pig placenta. Biochem. Biophys. Acta. 249: 345-352.

19. Norris, E. H. 1946. Anatomical evidence of prenatal function of the human parathyroid glands. Anat. Rec. 96: 129-141.

20. Boyd, J. D. 1950. Development of thyroid and parathyroid glands and the thymus. Ann. R. Coll. Surg. Engl. $7:$ : 455-471.

21. Scothorne, R. J. 1964. Functional capacity of fetal parathyroid glands with reference to their clinical use as homografts. Ann. N. Y. Acad. Sci. 120: 669-676.

22. Graham, R. W., and R. J. Scothorne. 1971. The onset of functional capacity in fetal guinea-pig parathyroid glands. Q. J. Exp. Physiol. Cogn. Med. Sci. 56: 41-45.

23. McFarlane, A. 1965. An experimental study of functional activity of the parathyroid gland of the chick embryo. J. Anat. 99: 922. (Abstr.)

24. Garel, J. M. 1970. Effêt de l'injection d'un sérum "antiparathormone" chez de foetus de rat. C. R. Hebd. Seances Acad. Sci. Ser. D. Sci. Natl. 271: 2364-2366.

25. Garel, J. M., P. Pic, and A. Jost. 1971. Action de la parathormone chez de foetus de rat. Ann. Endocrinol. 32 : 253-262.
26. Smith, F. G., Jr., D. P. Alexander, R. M. Buckle, H. G. Britton, and D. A. Nixon. 1972. Parathyroid hormone in foetal and adult sheep: the effect of hypocalcemia. J. Endocrinol. 53: 339-348.

27. Tan, C. M., A. Raman, and T. A. Sinnathyray. 1972. Serum ionic calcium levels during pregnancy. J. Obstet. Gynaecol. Br. Commonwe. 79: 694-697.

28. Cushard, W. G., Jr., M. A. Creditor, J. M. Canterbury, and E. Reiss. 1972. Physiologic hyperparathyroidism in pregnancy. J. Clin. Endocrinol. Metab. 34 : 767-771.

29. Graham, R. W., and R. J. Scothorne. 1970. Calcium homeostasis in the foetal guinea pig. Q.J. Exp. Physiol. Cogn. Med. Sci. 55: 44-53.

30. Graham, R. W., and G. P. Porter. 1971. Fetal-maternal plasma calcium relationships in the rabbit. $Q$.J. Cogn. Med. Sci. 56: 160-168.

31. Connelly, J. P., J. D. Crawford, and J. Watson. 1962. Studies of neonatal hyperphosphatemia. Pediatrics. 30: 425-432.

32. Linarelli, L. G., J. Bobik, and C. Bobik. 1972. Newborn urinary cyclic AMP and developmental renal responsiveness to parathyroid hormone. Pediatrics. 50: 14-23.

33. Tsang, R. C., L. I. Kleinman, J. M. Sutherland, and I. J. Light. 1972. Hypocalcemia in infants of diabetic mothers. J. Pediatr. 80: 384-395.

34. Graham, G. G., L. A. Barness, and P. Gyorgy. 1953. Serum calcium and inorganic phosphate in the newborn infant and their relation to different feedings. J. Pediatr. 42: 401-408.

35. Craig, W. S. 1958. Clinical signs of neonatal tetany: with especial reference to their occurrence in newborn babies of diabetic mothers. Pediatrics. 22: 297-308.

36. Radde, I. C., D. K. Parkinson, B. Hoffken, K. E. Apiah, and W. B. Hanley. 1972. Calcium ion activity in the sick neonate: effect of bicarbonate administration and exchange transfusion. Pediatr. Res. 6: 43-49.

37. Paunier, L., I. C. Radde, S. W. Kooh, P. E. Conen, and D. Fraser. 1968. Primary hypomagnesemia with secondary hypocalcemia in an infant. Pediatrics. 41: 385-402.

38. Salet, J., C. Polonovski, F de Goyon, G. Pean, B. Melekian, and J. P. Fournet. 1966. Tetanie hypocalcemique recidivante par hypomagnesemie congenitale, une maladie metabolique nouvelle. Arch. Fr. Pediatr. 23 : 749-768.

39. Estep, H., W. A. Shaw, C. Watlington, R. Hobe, W. Holland, and S. G. Tucker. 1969. Hypocalcemia due to hypomagnesemia and reversible parathyroid hormone unresponsiveness. J. Clin. Endocrinol. Metab. 29: 842848.

40. Muldowney, F. P., T. J. McKenna, L. H. Kyle, R. Freaney, and M. Swan. 1970. Parathormone-like effect of magnesium replenishment in steatorrhea. N. Engl. J. Med. 281: 61-80.

41. J. Salet, and J. P. Fournet. 1970. Les hypomagnesemies neo-natales. Ann. Pediatr. (Paris). $17: 837-845$.

42. Jones, K. H., and P. Fourman. 1966. Effects of infusions of magnesium and of calcium in parathyroid insufficiency. Clin. Sci. (Oxf.). 30: 139-150. 